\title{
Heat inactivation partially preserved barrier and immunomodulatory effects of Lactobacillus gasseri LA806 in an in vitro model of bovine mastitis
}

\author{
F. Blanchet ${ }^{1,2}$, L. Rault ${ }^{1}$, V. Peton ${ }^{1,3}$, Y. Le Loir ${ }^{1}$, C. Blondeau ${ }^{2}$, L. Lenoir ${ }^{2}$, M. Dubourdeaux ${ }^{2}$ and S. Even ${ }^{1 *}$ \\ ${ }^{1}$ INRAE, Institut Agro, STLO, Rennes, 35042, France; ${ }^{2}$ Groupe PiLeJe, 37 Quai de Grenelle 75015 Paris, France; ${ }^{3}$ Wamine, \\ 20, rue du Docteur-Finlay, 75738 Paris Cedex 15, France; sergine.even@inrae.fr
}

Received: 23 July 2020 / Accepted: 16 September 2020

(c) 2020 Wageningen Academic Publishers

RESEARCH ARTICLE

\begin{abstract}
Probiotics could help combat infections and reduce antibiotic use. As use of live bacteria is limited in some cases by safety or regulatory concerns, the potential of inactivated bacteria is worth investigating. We evaluated the potential of live and heat-inactivated Lactobacillus gasseri LA806 to counteract Staphylococcus aureus and Escherichia coli infection cycles in an in vitro model of bovine mastitis. We assessed the ability of live and inactivated LA806 to impair pathogen colonisation of bovine mammary epithelial cells (bMECs) and to modulate cytokine expression by pathogen-stimulated bMECs. Live LA806 induced a five-fold decrease in S. aureus adhesion and internalisation (while not affecting $E$. coli colonisation) and decreased pro-inflammatory cytokine expression by S. aureus-stimulated bMECs (without interfering with the immune response to $E$. coli). The ability of inactivated LA806 ability to diminish S. aureus colonisation was two-fold lower than that of the live strain, but its anti-inflammatory properties were barely impacted. Even though LA806 effects were impaired after inactivation, both live and inactivated LA806 have barrier and immunomodulatory properties that could be useful to counteract S. aureus colonisation in the bovine mammary gland. As S. aureus is involved in various types of infection, LA806 potential would worth exploring in other contexts.
\end{abstract}

OPEN ACCESS (C) (i) (9)(2)

Keywords: probiotics, mammary infection, immunomodulation, lactic acid bacteria

\section{Introduction}

In the last decades, probiotics have been widely investigated for the treatment and prevention of human and animal diseases. Bacteria belonging to the Lactobacillus and Bifidobacterium genera are the most commonly used microorganisms due to their long history of safe use and valuable benefits for health (Brodmann et al., 2017; Melo Pereira et al., 2018). Some bacteria display properties useful for fighting pathogens, such as competitive adhesion to the epithelium, production of antimicrobial substances, competition for nutrients, coaggregation with pathogens, modulation of virulence expression in pathogens and/ or modulation of the host immune system (BermudezBrito et al., 2012; Even et al., 2014; Melo Pereira et al., 2018). Consequently, probiotics are considered as a means of combating infectious diseases and reducing massive antibiotic use in both humans and domesticated animals.
Bovine mastitis is a major infectious disease responsible for considerable economic losses in dairy farms and throughout the milk production chain (Bouchard et al., 2013). Mastitis is an inflammation of the mammary gland generally due to bacterial infection. Staphylococcus aureus and Escherichia coli are among the main pathogens involved in ruminant mastitis. Prophylactic and curative treatments that are predominantly based on hygienic procedures and antibiotics are not fully effective, prompting the need for alternative or complementary strategies (Francoz et al., 2017; Peton and Le Loir, 2014). Several studies have reported valuable characteristics of selected bacterial strains in the context of bovine mastitis (Armas et al., 2017; Crispie et al., 2008; Klostermann et al., 2008; Malvisi et al., 2016; NaderMacías et al., 2008; Pellegrino et al., 2017; Souza et al., 2018; Wang et al., 2017). Our group showed that certain Lactobacillus strains can impair pathogen adhesion to and internalisation into bovine mammary epithelial cells 
(bMECs) and exhibit anti-inflammatory properties when incubated with pathogen-stimulated bMECs by decreasing the expression of several pro-inflammatory cytokines (Bouchard et al., 2013, 2015; Souza et al., 2018).

Although these results are promising and the bacteria used have a Generally Recognized as Safe (GRAS) or a Qualified Presumption of Safety (QPS) status, the use of live bacteria is a source of concern as such bacteria could have at least a transient negative impact on animal health by causing inflammation and/or infection. This belief is corroborated by the results of certain in vivo studies. For example, intra-mammary infusion of a live Lactococcus lactis strain in mastitic dairy cows was as effective as antibiotic treatment in a field trial (Crispie et al., 2008; Klostermann et al., 2008), but this benefit was associated with a transient inflammation following stimulation of the mammary immune system (Beecher et al., 2009; Crispie et al., 2008). Likewise, infusion of another L. lactis strain into the ewe mammary gland led to a transient clearance of the pathogens in the gland, but also to an increase in the inflammatory status of the gland (Mignacca et al., 2017). A Lactobacillus perolens strain similarly provoked a transient pro-inflammatory reaction when infused into cows during lactation or the dry period (Frola et al., 2012, 2013). Whilst stimulation of the immune system by intra-mammary infusion of live bacteria is likely to favour elimination of the pathogen, at least transiently, an exacerbated immune stimulation may provoke clinical symptoms of mastitis (Mignacca et al., 2017). These contrasting results blur the boundary between the beneficial and deleterious effects of live bacteria infusion and challenge the use of live probiotic bacteria in the context of mastitis.

Bacterial viability is generally considered as a prerequisite for the functionality of probiotics (Aguilar-Toala et al., 2018; Terpou et al., 2019). According to the WHO/FAO definition, probiotics are 'live microorganisms which when administered in adequate amounts confer a health benefit on the host' (FAO/WHO, 2001). This definition therefore stipulates that probiotics must be 'live' to provide health benefits. However, whereas some studies have reported the need for bacteria to be alive to exert their effects (AguilarToalá et al., 2018; Brodmann et al., 2017; Douillard and Vos, 2019; Terpou et al., 2019), others have demonstrated that viability is not mandatory for all probiotic effects, as not all mechanisms are directly linked to viability, particularly when the effect depends on surface-exposed components (Aguilar-Toalá et al., 2018; Brodmann et al., 2017; Douillard and Vos, 2019; Terpou et al., 2019). In addition, it cannot be denied that non-viable (inactivated) bacteria may have advantages over live bacteria in terms of safety, by reducing the risk of microbial translocation, infection and inflammatory responses (Aguilar-Toalá et al., 2018; Catozzi et al., 2019; Piqué et al., 2019). The use of inactivated bacteria may therefore be safer - particularly in humans or animals with a weak immune system or under inflammatory conditions - and still valuable, provided that the beneficial effects of the bacteria are at least partially preserved.

In this in vitro study, we investigated the potential of Lactobacillus gasseri LA806 to counteract the infection cycle of $S$. aureus and $E$. coli within bMECs and determined whether the properties of this strain were preserved after heat inactivation. We evaluated the ability of L. gasseri LA806, either alive or inactivated, to impair pathogen adhesion to and internalisation into bMECs and to modulate bMEC inflammatory response. L. gasseri LA806 was selected for this study on the basis of previous observations in vitro showing its strong ability to adhere to intestinal epithelial cells (internal data) and to restore and reinforce the epithelial barrier (Alard et al., 2018).

\section{Materials and methods}

\section{Bacterial strains and culture conditions}

The strain L. gasseri LA806 from the Larena collection (PiLeJe Industrie, Paris, France) was used in this study, as well as two well-characterised strains, representative of two major mastitis pathogens: S. aureus Newbould 305 (hereafter referred to as NB305) and E. coli P4 (Bouchard et al., 2015; Peton and Le Loir, 2014).

L. gasseri LA806 was cultured in Man Rogosa Sharpe medium (MRS; pH 6.8; BD, Le Pont de Claix, France) at $37^{\circ} \mathrm{C}$ without shaking. S. aureus NB305 and E. coli $\mathrm{P} 4$ were cultured in brain heart infusion medium (BHI, pH 7.4; BD, Le Pont de Claix, France) at $37^{\circ} \mathrm{C}$ under agitation (180 rpm). Subcultures were washed once with phosphate-buffered saline (PBS) and suspended at different concentrations in a cell culture medium (DMEM/F12) for cell infection assays (see below). Bacterial concentrations in subcultures were estimated by spectrophotometric measurements at $650 \mathrm{~nm}$.

For some experiments, L. gasseri LA806 was inactivated by heat treatment at $70{ }^{\circ} \mathrm{C}$ for $10 \mathrm{~min}$ in DMEM, just before its addition to bMECs. Preliminary tests had identified these conditions as the mildest conditions capable of reducing the viable $L$. gasseri LA806 population below $20 \mathrm{cfu} / \mathrm{ml}$ (detection limit).

\section{Epithelial cells and culture conditions}

Two epithelial cell lines were used in this study. The MAC-T cell line ((Huynh et al., 1991); Nexia Biotechnologies, Quebec, Canada) has been widely used for invasion assays and was therefore retained for this study (Almeida et al., 1996). Cells were grown in T75 cell culture flasks in MAC-T medium corresponding to DMEM/F12 advanced medium (D. Dutscher, Brumath, France) supplemented with 
10\% heat-inactivated foetal calf serum (FCS), $100 \mathrm{U} / \mathrm{ml}$ penicillin, $10 \mathrm{mg} / \mathrm{ml}$ streptomycin, and $5 \mu \mathrm{g} / \mathrm{ml}$ insulin (D. Dutscher). Cells were incubated at $37^{\circ} \mathrm{C}$ in a humidified incubator with $5 \% \mathrm{CO}_{2}$. After attaining a confluent monolayer, they were treated with $0.05 \%$ trypsin (GibcoBRL, Grand Island, NY, USA), and suspended in fresh MAC-T medium. For adhesion and internalisation assays, cells were seeded in 12 -well plates $\left(2 \times 10^{5}\right.$ cells/well) and incubated for $24 \mathrm{~h}$ at $37{ }^{\circ} \mathrm{C}$ in $5 \% \mathrm{CO}_{2}$ to obtain a confluent monolayer.

The second epithelial cell line, PS, was used for immunomodulation assays. The PS cell line reportedly presents a better immune response to infection-associated stimuli compared to the MAC-T response (Roussel et al., 2015). PS cells were grown in PS growth medium corresponding to DMEM/F12 advanced medium (D. Dutcher) containing $10 \mathrm{ng} / \mathrm{ml}$ of insulin-like growth factor-1 (Peprotech, Rocky Hill, CT, USA), $5 \mathrm{ng} / \mathrm{ml}$ of fibroblast growth factor (Peprotech), $5 \mathrm{ng} / \mathrm{ml}$ of EGF (Sigma-Aldrich, Saint Louis, MO, USA), $1 \mu \mathrm{g} / \mathrm{ml}$ of hydrocortisone (Sigma-Aldrich), 20 $\mathrm{mM}$ of HEPES buffer (D. Dutcher) and $2 \mathrm{mM}$ of glutamine (Gibco, Waltham, MA, USA). Cells were incubated at $37^{\circ} \mathrm{C}$ in a humidified incubator with $5 \% \mathrm{CO}_{2}$. After attaining a confluent monolayer, they were treated with $0.05 \%$ trypsin (Gibco-BRL), and suspended in fresh PS growth medium. For immunomodulation assays, cells were seeded in a 12 -well plate at a concentration of $2 \times 10^{5}$ cells/well and incubated at $37^{\circ} \mathrm{C}$ in a humidified incubator with $5 \%$ $\mathrm{CO}_{2}$ for $48 \mathrm{~h}$ to obtain a confluent monolayer. They were then washed with Hank's Balanced Salt Solution (HBSS, Sigma-Aldrich) and incubated for $24 \mathrm{~h}$ in a stimulation medium: DMEM/F12 advanced medium containing $4 \mathrm{ng} / \mathrm{ml}$ hydrocortisone, $20 \mathrm{mM}$ HEPES buffer and $2 \mathrm{mM}$ glutamine.

\section{Adhesion and internalisation assays}

Adhesion and internalisation assays were adapted from those described by Bouchard and collaborators (Bouchard et al., 2013). Confluent monolayers of MAC-T cells $\left(2.5 \times 10^{5}\right.$ cells/well) were washed twice in PBS. Cells were incubated at $37{ }^{\circ} \mathrm{C}$ in $5 \% \mathrm{CO}_{2}$ in $1 \mathrm{ml}$ DMEM with L. gasseri LA806 at a multiplicity of infection (MOI) of 400:1 or 2,000:1 and S. aureus NB305 or E. coli P4 at a MOI of 100:1. Adhesion and internalisation were measured 1 and $2 \mathrm{~h}$ after infection, respectively.

For the adhesion assays, MAC-T monolayers were washed four times with PBS and treated with $0.05 \%$ trypsin for $5 \mathrm{~min}$ at $37^{\circ} \mathrm{C}$. Cells were centrifuged for $5 \mathrm{~min}$ at $800 \mathrm{~g}$ and lysed by adding $100 \mu \mathrm{l}$ of $0.01 \%$ Triton in sterile water. The population of S. aureus NB305 and L. gasseri LA806 that adhered $(\mathrm{cfu} / \mathrm{ml})$ was determined using a previously described micromethod (Baron et al., 2006; Bouchard et al., 2013). The L. gasseri LA806 population was determined on MRS (pH 5.4) and incubated anaerobically for $48 \mathrm{~h}$ at $37^{\circ} \mathrm{C}$.
The S. aureus NB305 and E. coli $\mathrm{P} 4$ populations (cfu/ml) were determined on mannitol salt agar (MSA; D. Dutscher) and MacConkey agar (Torrejon de Ardoz, Madrid, Spain), respectively, after $24 \mathrm{~h}$ of incubation at $37^{\circ} \mathrm{C}$. It should be noted that the adhered and internalised populations of S. aureus NB305 $1 \mathrm{~h}$ post-infection were taken into account in the final count of the adhered population. The internalised population was indeed very small compared to the adhered population $1 \mathrm{~h}$ after infection (data not shown) and even $2 \mathrm{~h}$ after infection ( 10 fold smaller, see Figure 1 legend) and could therefore be neglected. The results of an adhesion assay of $S$. aureus NB305 alone were used as the reference. Adhesion rates were defined as the adhered S. aureus NB305 population in the presence of L. gasseri LA806 relative to the adhered S. aureus NB305 population in the reference experiment.

For the internalisation assays, cells were washed four times with PBS, incubated for an additional $2 \mathrm{~h}$ in DMEM containing gentamicin $(100 \mu \mathrm{g} / \mathrm{ml}$; Pan Biotech, Aidenbach, Germany). This step resulted in the killing of extracellular bacteria and allowed numeration of the internalised bacterial population only. The MAC-T monolayers were subsequently washed four times with PBS, treated with trypsin, centrifuged for $5 \mathrm{~min}$ at $800 \times g$ and lysed in $0.01 \%$ Triton. Internalised populations of L. gasseri LA806, S. aureus NB305 and E. coli $\mathrm{P} 4$ (cfu/ml) were determined as described for the adhesion assays.

\section{Determination of adhered heat-inactivated Lactobacillus gasseri LA806 population}

The adhered heat-inactivated L. gasseri LA806 population was determined by quantitative PCR in adhesion assays as described above. After Triton treatment, samples were washed in 9 volumes of buffered peptone water, centrifuged for $5 \mathrm{~min}$ at $8,000 \times \mathrm{g}$ and stored at $-20{ }^{\circ} \mathrm{C}$ until DNA extraction. The cell pellets were suspended in $50 \mu \mathrm{l} \mathrm{TE}$ buffer (20 mM Tris HCl, $2 \mathrm{mM}$ EDTA) and transferred into tubes containing $200 \mu \mathrm{l}$ lysis buffer (TE buffer containing $1 \%$ Triton) and $200 \mathrm{mg}$ zirconium beads (VWR, FontenaySous-Bois, France). Cells were disrupted using a Precellys Evolution homogeniser (Bertin Instruments, Montigny-leBretonneux, France) by performing three cycles of $30 \mathrm{~s}$ at $6,800 \mathrm{rpm}$ and $30 \mathrm{~s}$ on ice. After centrifugation at $4{ }^{\circ} \mathrm{C}$ for $5 \mathrm{~min}$ at $16,000 \times g$, lysates were treated with proteinase $K$ and DNA was extracted using a DNeasy blood and tissue kit and a Qiacube automated purification system (Qiagen, Hilden, Germany) according to the supplier's recommendations.

The L. gasseri LA806 population adhering to bMECs was determined by qPCR on the total DNA extracted using a standard range of pure L. gasseri LA806 DNA (expressed as the copy number of chromosome). The reaction mixture for qPCR contained SsoAdvanced Universal SYBR ${ }^{\oplus}$ Green 
Supermix (1×, Bio-Rad, Hercules, CA, USA), each primer $(0.5 \mu \mathrm{M})$ and a cDNA template. The primers LgBLX_gpmA FOR (5'-TCCACACATCGTTCCTAAGGC-3') and LgBLX_ gpmA_REV (5'-GCCGTCAAGTAAATCTGGAGC-3'), targeting phosphoglyceromutase, were used as forward and reverse primers, respectively. Thermal cycling consisted of $30 \mathrm{~s}$ at $98^{\circ} \mathrm{C}$, followed by 40 cycles of $10 \mathrm{~s}$ at $95^{\circ} \mathrm{C}$ and $30 \mathrm{~s}$ at $60^{\circ} \mathrm{C}$. Primer specificity was confirmed by lack of amplification on $S$. aureus genomic DNA.

\section{Immunomodulation assays}

The immunomodulatory properties of L. gasseri LA806, either alive or heat-inactivated, were explored essentially as previously described (Souza et al., 2018). Confluent monolayers of PS cells at $2.5 \times 10^{5}$ cells/well were washed twice with HBSS and incubated with L. gasseri LA806 at a MOI of 100:1 or 1000:1 alone and with S. aureus NB305 or E. coli $\mathrm{P} 4$ at a MOI of 30:1 in DMEM. After $2 \mathrm{~h}$, cells were washed twice with HBSS and incubated with stimulation medium containing $100 \mu \mathrm{g} / \mathrm{ml}$ gentamicin for $2 \mathrm{~h}$ to kill adhered extracellular bacteria. They were then washed three times with HBSS and incubated with stimulation medium containing $25 \mu \mathrm{g} / \mathrm{ml}$ gentamicin for an additional $4 \mathrm{~h}$ to complete a total period of $8 \mathrm{~h}$ post-infection. After the incubation period, either 2 or $8 \mathrm{~h}$ post-infection, cells were washed once with HBSS and then lysed with the RLT buffer of the RNeasy Mini Kit (Qiagen) for subsequent RNA extraction.

Total RNA was extracted using an RNeasy Mini Kit (Qiagen) according to the manufacturer's recommendations. Contaminating DNA was eliminated using DNA-free ${ }^{\mathrm{mm}}$ DNase Removal Treatment and Reagents kit (Life Technologies, Waltham, MA, USA). $1 \mu \mathrm{g}$ DNAse-treated RNA was used for reverse transcription using a $\mathrm{qScript}^{\mathrm{m}}{ }^{\mathrm{m}} \mathrm{cDNA}$ Synthesis Kit (Quanta Biosciences, Beverly, MA, USA), according to the manufacturer's recommendations.

qRT-PCR was performed using a CFX96 ${ }^{\text {min }}$ Real-Time PCR Detection System (Bio-Rad, Hercules, USA). Targeted genes included interleukin (IL)-1 $\alpha$ (IL-1 $\alpha$ ), IL-6, IL-8, tumour necrosis factor- $\alpha$ (TNF- $\alpha)$, lingual antimicrobial peptide (LAP), tracheal antimicrobial peptide (TAP), $\beta$-defensin 1 (DEF 1 1), nuclear factor $\mathrm{\kappa B}(\mathrm{NF} \kappa \mathrm{B})$ and nucleotide-binding oligomerisation domain 2 (NOD2). Primer sequences have already been published (Souza et al., 2018). PCR were performed as previously described. The genes coding for tyrosine 3-monooxygenase/tryptophan 5-monooxygenase activation protein, zeta polypeptide (YWHAZ), ribosomal protein L19 (RPL19) and peptidylprolyl isomerase A (PPIA) were used for normalisation as previously described (Souza et al., 2018).

\section{Statistical analysis}

Statistical analysis was performed using R software (http:// www.R-project.org). Effects of L. gasseri LA806 on pathogen adhesion and internalisation were assessed by a one-way ANOVA, followed by Tukey's multiple comparison test. Differences between treatments were assessed considering as statistically significant a $P$-value of less than 0.05 . Effects of pathogens and L. gasseri LA806 on interleukin and defensin expression were assessed by two-way ANOVA, using the presence of pathogens (none/E.coli/S.aureus) and L. gasseri LA806 (none/L.gasseri MOI 100×/L. gasseri MOI $1000 \times$ ) as factors. Differences between treatments were assessed considering as statistically significant a $P$-value of less than 0.05. Each experiment was conducted in biological triplicate.

\section{Results}

\section{Live Lactobacillus gasseri LA806 inhibit colonisation of epithelial cells by Staphylococcus aureus NB305 but not by Escherichia coli P4}

The assay was performed with S. aureus NB305 and E. coli $\mathrm{P} 4$, two representative strains of major pathogens implicated in bovine mastitis. L. gasseri LA806 at a MOI of 400:1 or 2000:1 was co-incubated with the pathogens on epithelial cells (MAC-T cell line) for 1 and $2 \mathrm{~h}$ for the assessment of adhesion and internalisation, respectively. A significant five-fold decrease in both the adhesion and internalisation of $S$. aureus NB305 was observed after its co-incubation with L. gasseri LA806 at a MOI of 2000:1 (Figure 1A and B), L. gasseri LA806 having no effect at a MOI of 400:1. In contrast, regardless of the MOI, L. gasseri LA806 had no significant effect on the adhesion or internalisation of E. coli P4 (Supplementary Figure S1).

\section{Live Lactobacillus gasseri LA806 displayed anti- inflammatory properties}

The immunomodulatory properties of L. gasseri LA806 were determined by evaluating the immune response of epithelial cells (PS cell line) after infection by $S$. aureus NB305 and E. coli $\mathrm{P} 4$ in the presence or absence of L. gasseri LA806. The expression of pro-inflammatory cytokines (IL$1 \alpha$, IL-6, IL- 8 and TNF- $\alpha$ ), antimicrobial peptides (DEF $\beta 1$, LAP, TAP) and transcription factors (NOD2 and NFKB) was measured. A low but significant expression of IL-8 was induced by L. gasseri LA806 at a MOI of 1000:1 at $2 \mathrm{~h}$, independently of the presence of a pathogen (Figure 2A). A similar trend was observed for IL-6 (Figure 2C). L. gasseri LA806 alone had no significant effect on the other cytokines at $2 \mathrm{~h}$ (Figure 2E, G) and no effect on any of the genes tested at $8 \mathrm{~h}$ (Figure 2B, D, F, H). 


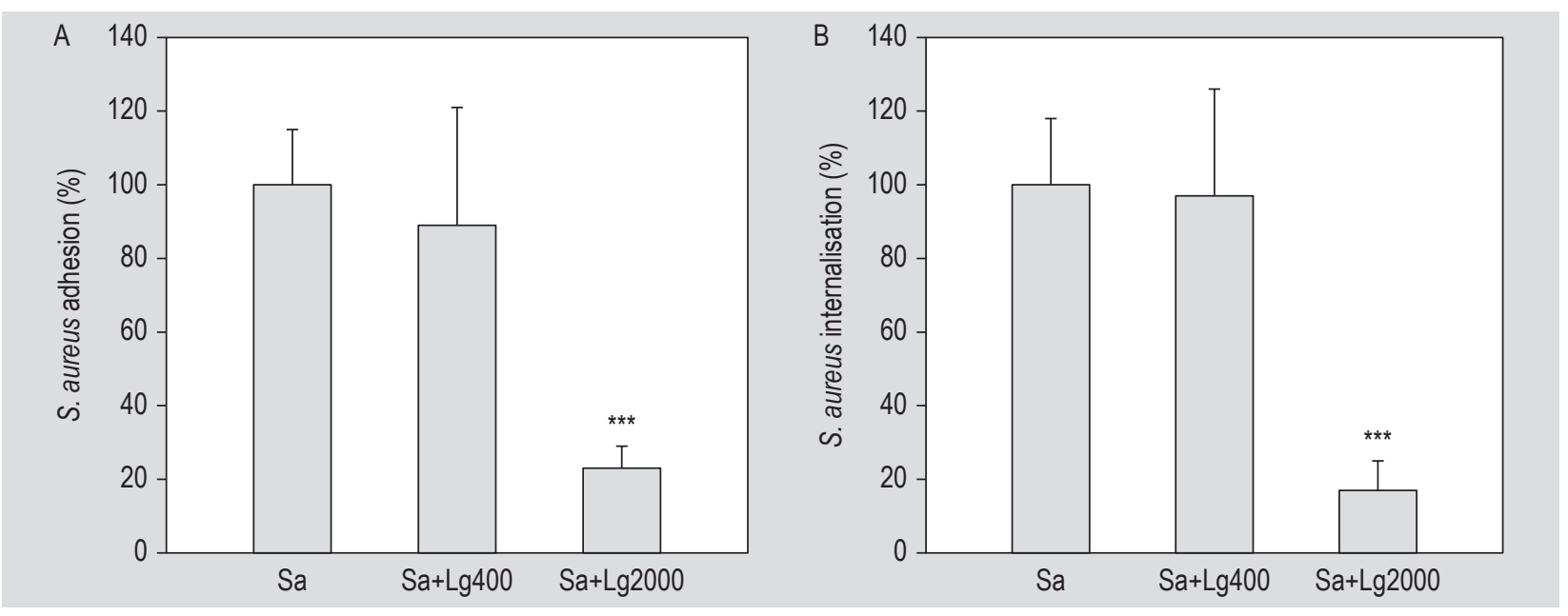

Figure 1. Effect of live Lactobacillus gasseri LA806 on Staphylococcus aureus N305 adhesion to and internalisation into bovine mammary epithelial cells. Pathogen adhesion $(A)$ and internalisation $(B)$ rates were measured at $1 \mathrm{~h}$ and $2 \mathrm{~h}$ post-infection, respectively. S. aureus NB305 (Sa) was used at a MOI of 100:1 and L. gasseri LA806 (Lg) at a MOI of 400:1 or 2,000:1. Adhesion and internalisation assays of $S$. aureus NB305 alone were used as a reference (control) and rates were then defined as the adhered or internalised S. aureus NB305 population in the presence of $L$. gasseri LA806 relative to the adhered or internalised S. aureus NB305 population of the reference experiment. Adhesion and internalisation rates of S. aureus NB305 alone were $3.4 \times 10^{6}$ and $4.8 \times 10^{5} \mathrm{cfu} /$ well respectively. Data are presented as means \pm standard deviations. Each experiment was performed in triplicate. The effects of $L$. gasseri LA806 on S. aureus NB305 adhesion and internalisation were assessed by a one-way ANOVA, followed by Tukey's multiple comparison test. ** $P<0.0005$. MOI: multiplicity of infection.

Whereas no effect was observed at 2 h, S. aureus NB305 induced a significant increase in the expression of all proinflammatory cytokines at $8 \mathrm{~h}$ (Figure 2). This induction was significantly reduced by L. gasseri LA806 at a MOI of 1000:1. E. coli P4 significantly induced the expression of IL- $1 \alpha$ and TNF- $\alpha$ at $2 \mathrm{~h}$ and a similar trend was observed for IL-8 (Figure 2A, C, E, G). E. coli P4 did not induce the expression of any pro-inflammatory cytokine at $8 \mathrm{~h}$ (Figure 2B, D, F, H). L. gasseri LA806 did not interfere with the effects of $E$. coli on pro-inflammatory cytokines at either 2 or $8 \mathrm{~h}$. The significant effects are summarised in Table 1.

A significant induction of antimicrobial peptides (DEF $\beta 1$, LAP and TAP) was observed when cells were infected by $E$. coli at $8 \mathrm{~h}$, with no modulatory effect of L. gasseri LA806 (Supplementary Figure S2). This effect was not observed with $S$. aureus. No variation in expression of NOD2 and $\mathrm{NF}-\kappa \mathrm{B}$ was detected under the conditions tested (data not shown).

\section{Heat inactivation of Lactobacillus gasseri LA806 partially preserved its ability to inhibit colonisation by Staphylococcus aureus}

L. gasseri LA806 had no effect on E. coli P4 colonisation. Competition assays between heat-inactivated (HI) $L$. gasseri LA806 and pathogens for bMEC colonisation were therefore performed solely with $S$. aureus N305. A HI L. gasseri LA806 MOI of 2000:1 was used, which was effective in adhesion and internalisation competition experiments with the live strain. Heat inactivation reduced the ability of L. gasseri LA806 to inhibit both the adhesion and internalisation of $S$. aureus NB305 to bMECs (Figure $3)$; the ability of the HI strain was two-fold lower than that of the live strain.

To determine whether this lesser effect was due to a reduced ability of HI L. gasseri LA806 to adhere to epithelial cells, in line with a competition mechanism, adhesion of HI L. gasseri LA806 was assessed. Adhered populations of live and HI L. gasseri LA806 were quantified by qPCR after 1 and $2 \mathrm{~h}$ of incubation. Compared to the live strain, there was a four to five-fold decrease in the amount of $\mathrm{HI}$ L. gasseri LA806 cells that adhered to bMECs 1 and $2 \mathrm{~h}$ post-incubation (Figure S3). As a control, we evaluated by qPCR the effect of heat inactivation on the L. gasseri LA806 population using a pure culture of the strain (without incubation with epithelial cells; data not shown). Heat-inactivation induced a two-fold loss of the L. gasseri LA806 population as determined by qPCR. This latter result suggests that the four to five-fold decrease in the amount of HI L. gasseri LA806 cells that adhered to epithelial cells was partially, yet not entirely due to this population loss. Inactivation therefore induced a two-fold decrease in the ability of $L$. gasseri LA806 to adhere to epithelial cells. 

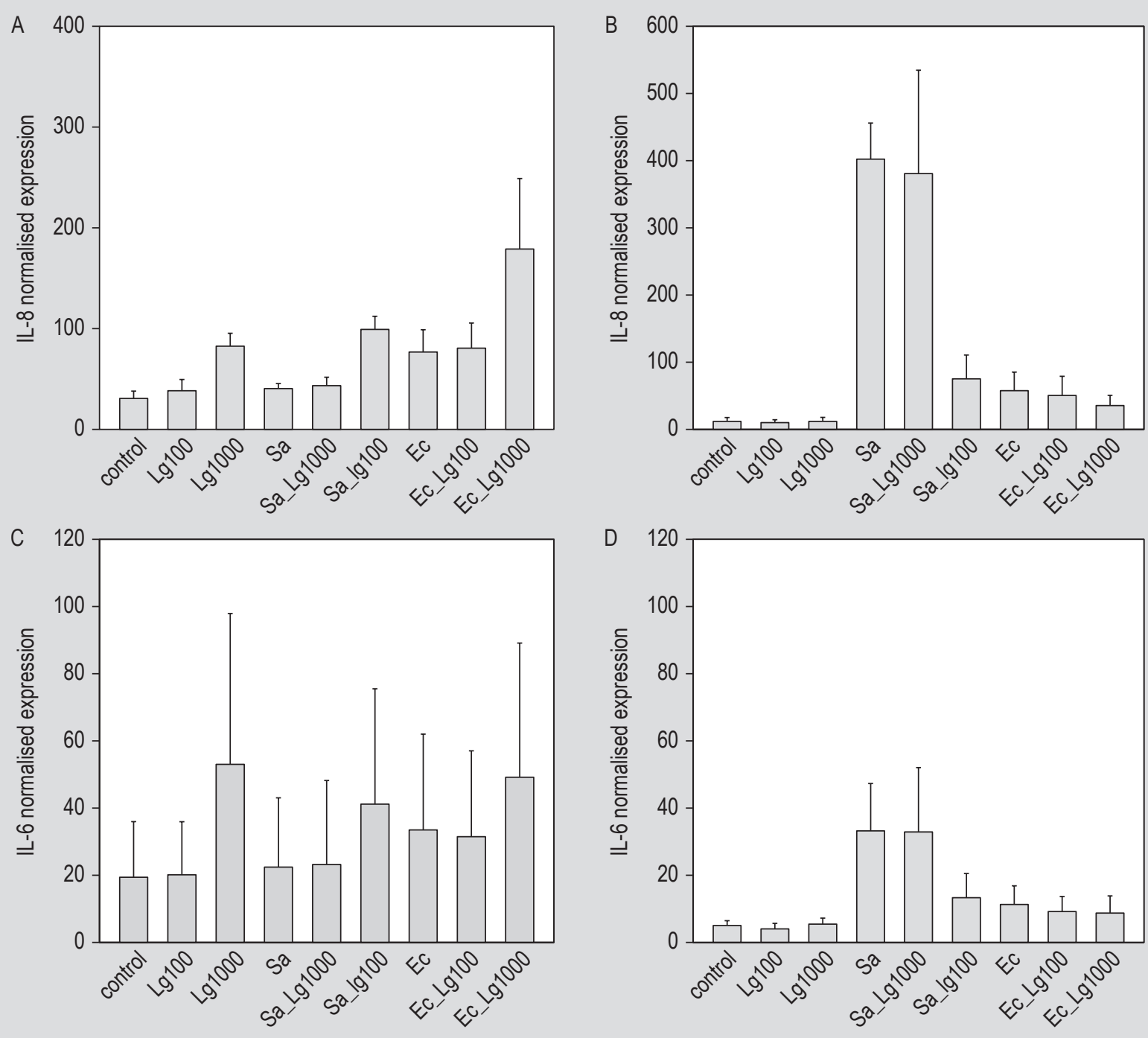

Figure 2. Impact of Lactobacillus gasseri LA806 (Lg) on interleukin (IL)-8 (A, B), IL-6 (C, D), tumour necrosis factor (TNF)- $\alpha$ (E, F) and IL-1a (G, H) expression by bovine mammary epithelial cells (bMECs) during infection by Staphylococcus aureus NB305 (Sa) or Escherichia coli P4 $(\mathrm{EC})$. bMECs were stimulated with pathogens at a MOI of 30:1 either alone or in the presence of $L$. gasseri LA806 at a MOI of 100:1 and 1.000:1. Expression was measured at $2 \mathrm{~h}(\mathrm{~A}, \mathrm{C}, \mathrm{E}, \mathrm{G})$ and $8 \mathrm{~h}$ (B, D, F, H) post-infection. Expression was determined as the normalised expression with regard to three control genes. Each experiment was performed in triplicate. The effects of each factor (i.e. the presence of a pathogen or L. gasseri LA806) and interactions between the two factors were assessed using a two-way analysis of variance. MOI = multiplicity of infection.

\section{Heat inactivation of Lactobacillus gasseri LA806 scarcely affected its immunomodulatory properties}

Overall review of the immunomodulatory properties of $\mathrm{HI}$ L. gasseri LA806 compared to the live strain indicates that most of the immunomodulatory effects of live L. gasseri LA806 were conserved following heat inactivation of the bacterial cells (Figure 2 and Supplementary Figure S4). Addition of HI L. gasseri LA806 at a MOI of 1000:1 induced a moderate increase in IL-6 at $2 \mathrm{~h}$, independently of the presence of a pathogen (Supplementary Figure S4C), in agreement with the trend observed with live L. gasseri LA806 (Figure 2C).
HI L. gasseri LA806 showed a significant inhibitory effect at $8 \mathrm{~h}$ on $S$. aureus-stimulated bMECs (Supplementary Figure $\mathrm{S} 4 \mathrm{~A}, \mathrm{~B})$, which is in line with the experiments with live L. gasseri LA806. The expression of all cytokines tested was indeed significantly reduced in the presence of HI L. gasseri LA806 at a MOI of 1000:1 and even at a MOI of 100:1 for IL-8 (Supplementary Figure S4B,D,F,H). Interestingly, HI L. gasseri LA806 at a MOI of 1000:1 significantly decreased the induction of TNF- $\alpha$ expression in the presence of E. coli at $2 \mathrm{~h}$ (Supplementary Figure S4E). This inhibition was not observed with live L. gasseri LA806 (Figure 2E, F). 

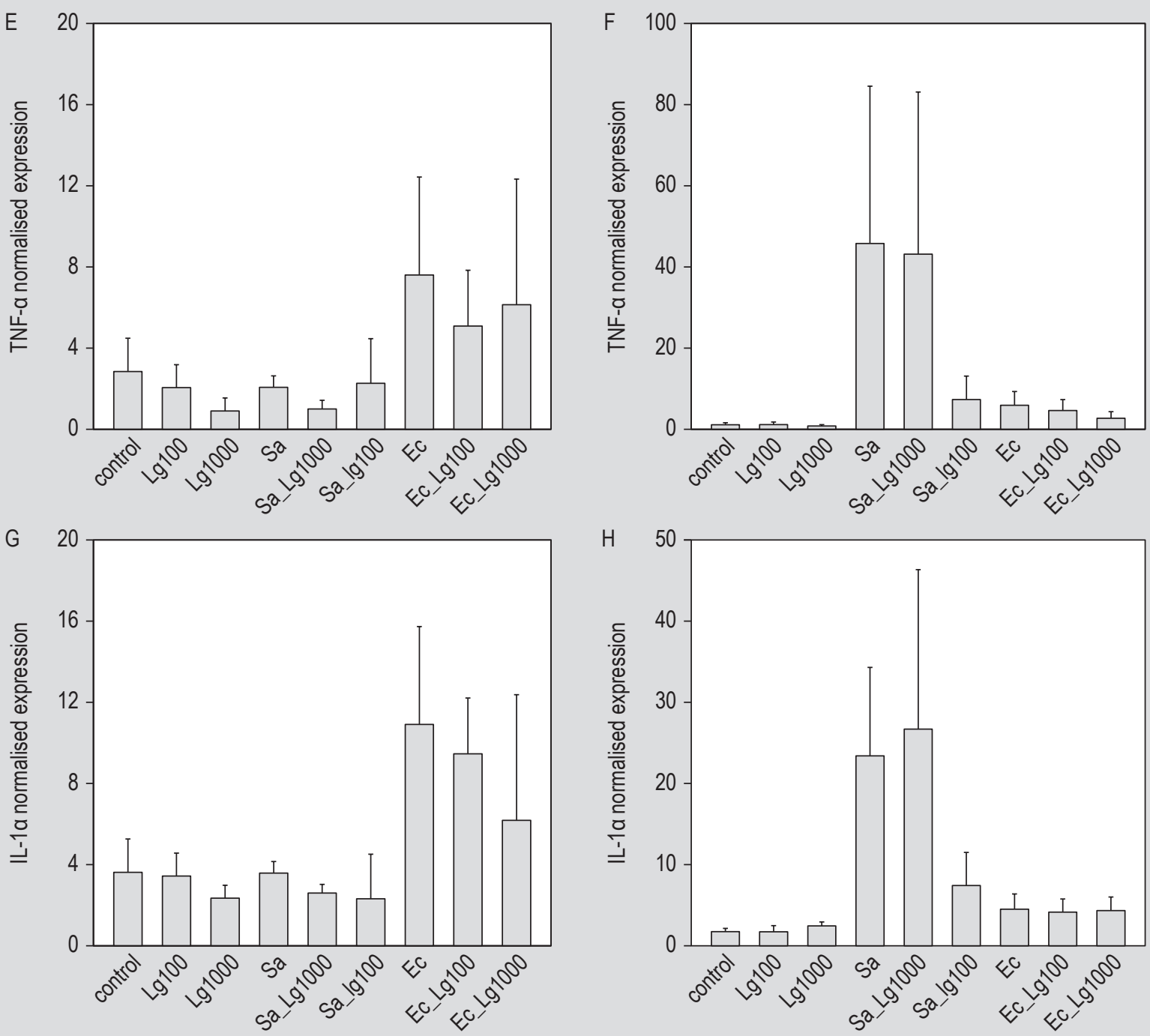

Figure 2. Continued.

Table 1. Summary of the significant effects ( $P$-values) of Lactobacillus gasseri LA806 $(\mathrm{Lg})$ on cytokine expression by bovine mammary epithelial cells during infection by Staphylococcus aureus NB305 or Escherichia coli P4. ${ }^{1}$

Factor

$\operatorname{Lg} 1000$

S. aureus

E. coli

S. aureus $\times \operatorname{Lg} 1000$
Significant effect on gene expression at $2 \mathrm{~h}$

IL-8 $\left.{ }^{* *}\right)$, IL $-6(P=0.0547)$

IL-8 $\left.(P=0.0513), \mathrm{IL}-1 \alpha{ }^{* * *}\right)$, TNF- $\alpha\left(^{*}\right)$
Significant effect on gene expression at $8 \mathrm{~h}$

IL-8 $\left(^{* * *}\right), \operatorname{IL}-6\left(^{* * *}\right), \operatorname{IL}-1 \alpha\left(^{* * *}\right)$, TNF- $\left.\alpha{ }^{(* *}\right)$

IL-8 $\left(^{* * *}\right), \mathrm{IL}-6\left(^{*}\right), \mathrm{IL}-1 \alpha\left(^{*}\right)$, TNF- $\alpha\left(^{*}\right)$

${ }^{1} \mathrm{IL}=$ interleukin; TNF = tumour necrosis factor. ${ }^{*} P<0.05,{ }^{* *} P<0.005,{ }^{* * *} P<0.0005$.

As observed in the experiments with live L. gasseri LA806, the $\mathrm{HI}$ bacteria did not modulate E. coli $\mathrm{P} 4$ induced antimicrobial peptide expression at $8 \mathrm{~h}$ (Supplementary Figure S5), or the expression of NOD2 and NF-kB in bMECs (data not shown).

\section{Discussion}

The highly problematic rise in antibiotic resistance forces us to consider alternative human and animal health strategies in order to reduce the use of antibiotics (WHO, 2015). 


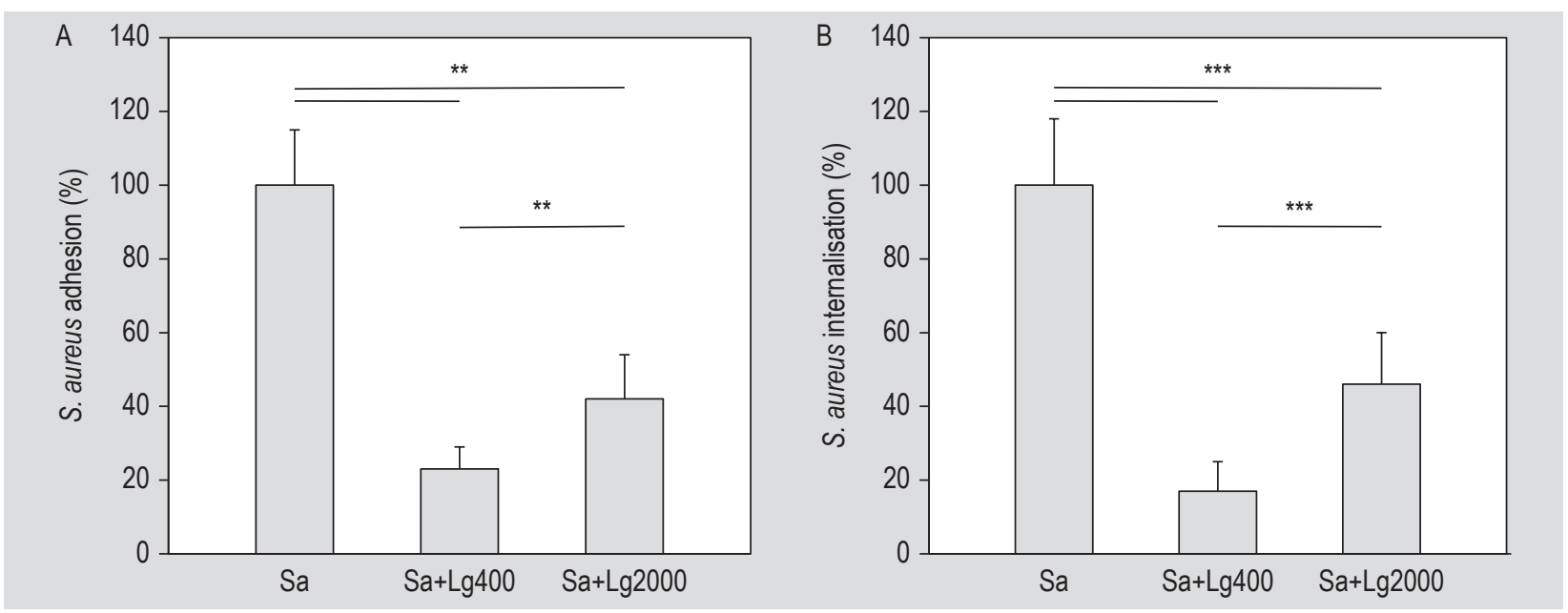

Figure 3. Effect of heat-inactivated (HI) Lactobacillus gasseri LA806 on Staphylococcus aureus N305 adhesion to and internalisation into bovine mammary epithelial cells. S. aureus adhesion $(A)$ and internalisation $(B)$ rates were measured $1 \mathrm{~h}$ and $2 \mathrm{~h}$ post-infection, respectively. S. aureus NB305 (Sa) was used at a MOI of 100:1 and L. gasseri LA806, either heat-inactivated (HI-Lg) or alive (Lg), at a MOI of 2000:1. The results of adhesion and internalisation assays with $S$. aureus alone were used as the reference (control). Rates were then defined as the adhered or internalised S. aureus NB305 population in the presence of L. gasseri LA806 either heat-inactivated or live, relative to the adhered or internalised S. aureus NB305 population of the reference experiment. Data are presented as means \pm standard deviations. Each experiment was performed in triplicate and differences between groups were assessed using a one-way analysis of variance followed by Tukey's range test. ${ }^{* *} P<0.005,{ }^{* *} P<0.0005$. MOl: multiplicity of infection.

In this context, the exploration of strategies involving probiotics has attracted interest in many areas, including bovine mammary gland health. Although probiotics are recognised to confer health benefits on the host, the WHO/ FAO also consider that they have four types of putative side effects: systemic infections, deleterious metabolic activities, gene transfer and excessive activation of the immune system, especially in immunocompromised individuals and neonates (Doron and Snydman, 2015; Piqué et al., 2019; Sanders et al., 2016). Bacterial inactivation could alleviate some of these safety concerns, while retaining the value of these bacteria if their beneficial effects are at least partially preserved. The results presented here reveal that the probiotic properties of L. gasseri LA806 assessed in an in vitro model of bovine mastitis are in part preserved after heat inactivation.

\section{Live Lactobacillus gasseri LA806 inhibits S. aureus colonisation of bMECs while hardly affecting Escherichia coli colonisation}

Interaction with L. gasseri LA806 resulted in a five-fold reduction of $S$. aureus NB305 adhesion to and internalisation into bMECs, whereas it did not alter those of E. coli $\mathrm{P} 4$. This ability of lactic acid bacteria (LAB) to prevent $S$. aureus colonisation of bMECs has been previously reported for several Lactobacillus casei strains (Bouchard et al., 2013) and for Lactococcus lactis V7 (Assis et al., 2015). Interestingly, as observed with L. gasseri LA806, L. lactis V7 did not modify E. coli adhesion rate but in contrast to L. gasseri LA806, it was able to reduce E. coli $\mathrm{P} 4$ internalisation, confirming that the ability to compete with pathogens for bMEC colonisation is species- and even strain-dependent (Bouchard et al., 2013). In accordance with this finding, one study did not report such a property of the L. lactis strain tested (Mignacca et al., 2017). Nevertheless, it should be noted that in this study, competition assays were performed with another bovine mammary epithelial cell line and with a lower LAB:cell ratio. Strain dependency, especially with regard to the pathogen, leads us to reject the hypothesis of a competition solely based on steric hindrance, as in such a case similar inhibition of adhesion should have been observed for $E$. coli. It rather supports a competition for specific sites on bMECs. This is in agreement with the existence of different mechanisms of interaction with bMECs for $E$. coli and $S$. aureus: different pathogenassociated molecular patterns (PAMPS) interact with different pattern recognition receptors (PRR) (Gilbert et al., 2013; Schukken et al., 2011; Védrine et al., 2018).

\section{Complex immunomodulatory properties of live Lactobacillus gasseri LA806: from pro- to anti- inflammatory profiles}

The immunomodulatory properties of L. gasseri LA806 were investigated on bMECs in the presence or absence of the pathogens at 2 and $8 \mathrm{~h}$ post-infection. This kinetic approach revealed complex interactions of $L$. gasseri LA806 with bMECs. At 8 h, L. gasseri LA806 had antiinflammatory effects, as revealed by a decrease in the expression of several pro-inflammatory cytokines (IL-8, IL-6, IL- $1 \alpha$ and TNF- $\alpha$ ) by $S$. aureus-stimulated bMECs. 
A similar anti-inflammatory profile was reported for $L$. casei BL23 at a lower S. aureus MOI (10:1) (Bouchard et al., 2013; Souza et al., 2018). However, a slight but yet significant increase in IL- 8 was observed at $2 \mathrm{~h}$ in the presence of L. gasseri LA806 (either alone or during co-infection with $S$. aureus or E. coli) and a similar trend was observed for IL-6, suggesting a transient pro-inflammatory profile of this L. gasseri strain. These results clearly emphasise the importance of analysing cytokine expression over time rather than at a single time-point to better understand the immunomodulatory properties of a given strain, as previously reported for pathogens (Fu et al., 2013; Günther et al., 2011) and LAB strains (Souza et al., 2018). In human peripheral blood mononuclear cells, L. gasseri LA806 induced a slight increase in IL-12 and interferon- $\gamma$ expression, while scarcely affecting IL-10 expression, suggesting a moderate pro-inflammatory profile in this model as well (Alard et al., 2018). We propose that in the mammary gland context, L. gasseri LA806 did not display anti-inflammatory properties per se, but rather provoked an early and moderate stimulation of the innate immune system. By adhering to bMECs and thus inhibiting S. aureus adhesion and internalisation, L. gasseri LA806 likely induced a lesser stimulation of pro-inflammatory cytokine expression by $S$. aureus.

E. coli-stimulated bMECs displayed cytokine expression kinetics differing from those of $S$. aureus-stimulated cells and notably, an earlier stimulation of pro-inflammatory cytokine expression, as previously reported (Günther et al., 2017; Schukken et al., 2011). Indeed, E. coli led to a transient induction of IL- $1 \alpha$, TNF- $\alpha$ and IL- 8 at $2 \mathrm{~h}$ postinfection. This effect, that was lost by $8 \mathrm{~h}$ post-infection, was followed by an induction of LAP, TAP and DEF $\beta 1$ defensin expression at 8 h. L. gasseri LA806 did not significantly interfere with the bMEC immune response to $E$. coli. This observation is consistent with the lack of effect of $L$. gasseri LA806 on the colonisation ability of the pathogen. At least L. gasseri LA806 did not impair the induction of defensins that contribute to combating pathogens. To a certain extent, it somehow complies with the primum non nocere principle.

\section{Heat-inactivated Lactobacillus gasseri LA806 retains beneficial properties}

Bacteria can be inactivated using different methods, such as heating, chemical treatment, gamma or UV radiation and sonication (Piqué et al., 2019). These treatments can affect cell structural components and most of the inactivated bacterial products contain more cellular lysate than cells per se (Piqué et al., 2019). Interaction of LAB with epithelial cells was reported to involve surface components of the bacteria (Sengupta et al., 2013). L. gasseri LA806 was thus inactivated with moderate heating $\left(10 \mathrm{~min}\right.$ at $\left.70{ }^{\circ} \mathrm{C}\right)$ in order to limit denaturation and preserve the ability of the strain to interact with bMECs.
Moderate heating led to partial loss of the ability of L. gasseri LA806 to inhibit $S$. aureus adhesion to and internalisation into bMECs (two-fold lower than that of the live bacteria). This is clearly the consequence of an impaired ability of $\mathrm{HI}$ L. gasseri LA806 to adhere to epithelial cells. The adhesion rate of HI L. gasseri LA806 at 1 and 2 h, as determined by qPCR, was approximatively two-fold lower than that of live L. gasseri LA806 after correction for the loss of signal due to heat treatment. Although the heat treatment was moderate, it likely denaturised cell wall surface components including those involved in the interaction with bMECs. Various cell surface components, such as proteins, peptidoglycans, teichoic acids and polysaccharides contribute to the interaction of LAB with epithelial cells (Piqué et al., 2019; Taverniti and Guglielmetti, 2011). A L. casei BL23 srtA2 mutant, srtA2 encoding a sortase, was less effective in inhibiting $S$. aureus adhesion to and internalisation into bMECs (Souza et al., 2017). This characteristic was associated with an altered abundance of LPXTG and moonlighting proteins at the surface of the srtA2 mutant strain as well as with modifications of the cell wall structure. Cell surface components also contribute to the immunomodulatory and anti- and pro-inflammatory properties of the strains. For example, components associated with peptidoglycans, such as teichoic acids, have been shown to elicit pro-inflammatory responses induced by LAB themselves and to inhibit the excessive inflammatory response induced by pathogens (Piqué et al., 2019; Taverniti and Guglielmetti, 2011).

HI L. gasseri LA806 was still able to significantly inhibit $S$. aureus colonisation, although with diminished efficacy. Interestingly, the immunomodulatory properties of $\mathrm{HI}$ L. gasseri LA806 were scarcely affected. The beneficial properties of L. gasseri LA806 were therefore at least partially preserved following heat inactivation. Inactivated strains have already been assessed in mastitis. One study showed a transient pro-inflammatory effect of intramammary infusion of a heat-inactivated Lactobacillus rhamnosus strain, revealed by an increase in somatic cell count and a slight modification of milk microbiota after six days (Catozzi et al., 2019). However, despite stimulation of the innate immune system, administration of the heatinactivated L. rhamnosus strain did not enhance pathogen clearance in this study. The use of inactivated bacteria has also been tested in gastrointestinal, dermatological and respiratory allergic diseases (Adams, 2010; Piqué et al., 2019), oropharyngeal and vaginal candidiasis (Pericolini et al., 2017; Roselletti et al., 2019), development of caries (Schwendicke et al., 2014), osteoarthritis (Henrotin et al., 2019), as well as for the stimulation of human immune cells or for their anti-inflammatory properties (Jensen et al., 2017). Beneficial properties maintained after inactivation include prevention of infections and competition with pathogens (Canducci et al., 2000). The results of these studies varied greatly, bacterial inactivation resulting 
either in conservation (Roselletti et al., 2019) or partial loss (Pericolini et al., 2017) of beneficial properties and even, in some studies, in superior efficacy of the inactivated bacterial strain evaluated versus the live strain (Jensen et al., 2017; Schwendicke et al., 2014). This variability probably reflects the mechanisms involved as well as differences in the protocol of inactivation used (Piqué et al., 2019).

In conclusion, this study revealed that L. gasseri LA806 has barrier and immunomodulatory properties that could be useful to counteract mammary gland infections caused by S. aureus and that the properties of this strain were at least partially preserved following moderate heat treatment. The use of an inactivated probiotic in this context could limit pathogen colonisation, attenuate inflammation and reduce tissue damage caused by $S$. aureus infection, likely with a lower risk of side effects due to the use of an inactivated strain. The potential of live and inactivated L. gasseri LA806 to counteract the infection cycle of $S$. aureus warrants confirmation in vivo. Furthermore, as S. aureus is implicated in numerous types of infection in both animals and humans, the potential of $L$. gasseri LA806 would be worth exploring in other contexts.

\section{Supplementary material}

Supplementary material can be found online at https://doi. org/10.3920/BM2020.0146.

Figure S1. Effect of Lactobacillus gasseri LA806 on Escherichia coli $\mathrm{P} 4$ adhesion to and internalisation into bovine mammary epithelial cells.

Figure S2. Impact of Lactobacillus gasseri LA 806 on DEF $\beta 1$, LAP and TAP expression by bovine mammary epithelial cells following infection by Staphylococcus aureus NB 305 (or Escherichia coli P4).

Figure S3. Effect of heat inactivation on Lactobacillus gasseri LA806 adhesion to bovine mammary epithelial cells.

Figure S4. Impact of heat inactivated Lactobacillus gasseri LA806 on IL-8, IL-6, TNF- $\alpha$ and IL-1 $\alpha$ expression by bovine mammary epithelial cells following infection by Staphylococcus aureus NB305 (or Escherichia coli P4).

Figure S5. Impact of heat inactivated Lactobacillus gasseri LA806 on DEF $\beta 1$, LAP and TAP expression by bovine mammary epithelial cells following infection by Staphylococcus aureus NB305 (or Escherichia coli P4).

\section{Acknowledgements}

We thank Vivien Paula Harry (independent medical writer and native English speaker) for writing and editorial assistance.

\section{Conflict of interest}

The authors declare no conflict of interest.

\section{References}

Adams, C.A., 2010. The probiotic paradox: live and dead cells are biological response modifiers. Nutrition Research Reviews 23: 37-46. https://doi.org/10.1017/S0954422410000090

Aguilar-Toalá, J.E., Garcia-Varela, R., Garcia, H.S., Mata-Haro, V., González-Córdova, A.F., Vallejo-Cordoba, B. and HernándezMendoza, A., 2018. Postbiotics: An evolving term within the functional foods field. Trends in Food Science and Technology 75: 105-114. https://doi.org/10.1016/j.tifs.2018.03.009

Alard, J., Peucelle, V., Boutillier, D., Breton, J., Kuylle, S., Pot, B., Holowacz, S. and Grangette, C., 2018. New probiotic strains for inflammatory bowel disease management identified by combining in vitro and in vivo approaches. Beneficial Microbes 9: 317-331. https://doi.org/10.3920/BM2017.0097

Almeida, R.A., Matthews, K.R., Cifrian, E., Guidry, A.J. and Oliver, S.P., 1996. Staphylococcus aureus invasion of bovine mammary epithelial cells. Journal of Dairy Science 79: 1021-1026. https://doi. org/10.3168/jds.S0022-0302(96)76454-8

Armas, F., Camperio, C. and Marianelli, C., 2017. In vitro assessment of the probiotic potential of Lactococcus lactis LMG 7930 against ruminant mastitis-causing pathogens. PLoS ONE 12: e0169543. https://doi.org/10.1371/journal.pone.0169543

Assis, B.S., Germon, P., Silva, A.M., Even, S., Nicoli, J.R. and Le Loir, Y., 2015. Lactococcus lactis V7 inhibits the cell invasion of bovine mammary epithelial cells by Escherichia coli and Staphylococcus aureus. Beneficial Microbes 6: 879-886. https://doi.org/10.3920/ BM2015.0019

Baron, F., Cochet, M.-F., Ablain, W., Grosset, N., Madec, M.-N., Gonnet, F., Jan, S. and Gautier, M., 2006. Rapid and cost-effective method for micro-organism enumeration based on miniaturization of the conventional plate-counting technique. Le Lait 86: 251-257. https://doi.org/10.1051/lait:2006005

Beecher, C., Daly, M., Berry, D.P., Klostermann, K., Flynn, J., Meaney, W., Hill, C., McCarthy, T.V., Ross, R.P. and Giblin, L., 2009. Administration of a live culture of Lactococcus lactis DPC 3147 into the bovine mammary gland stimulates the local host immune response, particularly IL-1beta and IL-8 gene expression. Journal of Dairy Research 76: 340-348. https://doi.org/10.1017/ S0022029909004154

Bermudez-Brito, M., Plaza-Díaz, J., Muñoz-Quezada, S., GómezLlorente, C. and Gil, A., 2012. Probiotic mechanisms of action. Annals of Nutrition and Metabolism 61: 160-174. https://doi. org/10.1159/000342079

Bouchard, D.S., Rault, L., Berkova, N., Le Loir, Y. and Even, S., 2013. Inhibition of Staphylococcus aureus invasion into bovine mammary epithelial cells by contact with live Lactobacillus casei. Applied and Environmental Microbiology 79: 877-885. https://doi.org/10.1128/ AEM.03323-12 
Bouchard, D.S., Seridan, B., Saraoui, T., Rault, L., Germon, P., GonzalezMoreno, C., Nader-Macias, F.M.E., Baud, D., François, P., Chuat, V., Chain, F., Langella, P., Nicoli, J., Le Loir, Y. and Even, S., 2015. Lactic acid bacteria isolated from bovine mammary microbiota: potential allies against bovine mastitis. PLoS ONE 10: e0144831. https://doi.org/10.1371/journal.pone.0144831

Brodmann, T., Endo, A., Gueimonde, M., Vinderola, G., Kneifel, W., De Vos, W.M., Salminen, S. and Gómez-Gallego, C., 2017. Safety of novel microbes for human consumption: practical examples of assessment in the European Union. Frontiers in Microbiology 8: 1725. https://doi.org/10.3389/fmicb.2017.01725

Canducci, F., Armuzzi, A., Cremonini, F., Cammarota, G., Bartolozzi, F., Pola, P., Gasbarrini, G. and Gasbarrini, A., 2000. A lyophilized and inactivated culture of Lactobacillus acidophilus increases Helicobacter pylori eradication rates. Alimentary Pharmacology and Therapeutics 14: 1625-1629.

Catozzi, C., Cuscó, A., Lecchi, C., De Carlo, E., Vecchio, D., Martucciello, A., D’Angelo, L., Francino, O., Sanchez Bonastre, A. and Ceciliani, F., 2019. Impact of intramammary inoculation of inactivated Lactobacillus rhamnosus and antibiotics on the milk microbiota of water buffalo with subclinical mastitis. PLoS ONE 14: e0210204. https://doi.org/10.1371/journal.pone.0210204.

Crispie, F., Alonso-Gómez, M., O’Loughlin, C., Klostermann, K., Flynn, J., Arkins, S., Meaney, W., Paul Ross, R. and Hill, C., 2008. Intramammary infusion of a live culture for treatment of bovine mastitis: effect of live lactococci on the mammary immune response. Journal of Dairy Research 75: 374-384. https://doi.org/10.1017/ S0022029908003385

De Melo Pereira, G.V., De Oliveira Coelho, B., Magalhães Júnior, A.I., Thomaz-Soccol, V. and Soccol, C.R., 2018. How to select a probiotic? A review and update of methods and criteria. Biotechnology Advances 36: 2060-2076. https://doi.org/10.1016/j. biotechadv.2018.09.003

Doron, S. and Snydman, D.R., 2015. Risk and safety of probiotics. Clinical Infectious Diseases 60, Suppl. 2: S129-134. https://doi. org/10.1093/cid/civ085

Douillard, F.P. and De Vos, M., 2019. Biotechnology of healthpromoting bacteria. Biotechnology Advances 37: 107369. https:// doi.org/10.1016/j.biotechadv.2019.03.008.

Even, S., Bouchard, D. and Le Loir, Y., 2014. Lactic acid bacteria to modulate virulence expression in pathogenic bacteria: an alternative to killing? In: Pessione, E. (ed.) Interactive probiotics. CRC Press, Boca Raton, FL, USA, pp. 52-80.

Food and Agriculture Organisation / World Health Organisation (FAO/ WHO), 2001. Health and nutritional properties of probiotics in food including powder milk with live active lactic acid bacteria. Report of joint FAO/WHO Expert Consultation on evaluation and health and nutritional properties of probiotics in food including powder milk with live lactic acid bacteria. FAO Food and Nutrition Paper 85, FAO/WHO, Rome, Italy.

Francoz, D., Wellemans, V., Dupré, J.P., Roy, J.P., Labelle, F., Lacasse, P. and Dufour, S., 2017. Invited review: a systematic review and qualitative analysis of treatments other than conventional antimicrobials for clinical mastitis in dairy cows. Journal of Dairy Science 100: 7751-7770. https://doi.org/10.3168/jds.2016-12512
Frola, I.D., Pellegrino, M.S., Espeche, M.C., Giraudo, J.A., NaderMacias, M.E. and Bogni, C.I., 2012. Effects of intramammary inoculation of Lactobacillus perolens CRL1724 in lactating cows' udders. Journal of Dairy Research 79: 84-92. https://doi.org/10.1017/ S0022029911000835

Frola, I.D., Pellegrino, M.S., Magnano, G., Giraudo, J.A., Espeche, M.C., Nader-Macias, M.E.F. and Bogni, C.I., 2013. Histological examination of non-lactating bovine udders inoculated with Lactobacillus perolens CRL 1724. Journal of Dairy Research 80: 28-35. https://doi.org/10.1017/S0022029912000581

Fu, Y., Zhou, E., Liu, Z., Li, F., Liang, D., Liu, B., Song, X., Zhao, F., Fen, X., Li, D., Cao, Y., Zhang, X., Zhang, N. and Yang, Z., 2013. Staphylococcus aureus and Escherichia coli elicit different innate immune responses from bovine mammary epithelial cells. Veterinary Immunology and Immunopathology 155: 245-252. https://doi. org/10.1016/j.vetimm.2013.08.003

Gilbert, F.B., Cunha, P., Jensen, K., Glass, E.J., Foucras, G., RobertGranié, C., Rupp, R. and Rainard, P., 2013. Differential response of bovine mammary epithelial cells to Staphylococcus aureus or Escherichia coli agonists of the innate immune system. Veterinary Research 44: 40. https://doi.org/10.1186/1297-9716-44-40

Günther, J., Esch, K., Poschadel, N., Petzl, W., Zerbe, H., Mitterhuemer, S., Blum, H. and Seyfert, H.-M., 2011. Comparative kinetics of Escherichia coli- and Staphylococcus aureus-specific activation of key immune pathways in mammary epithelial cells demonstrates that $S$. aureus elicits a delayed response dominated by interleukin- 6 (IL-6) but not by IL-1A or tumor necrosis factor alpha. Infection and Immunity 79: 695-707. https://doi.org/10.1128/IAI.01071-10

Günther, J., Petzl, W., Bauer, I., Ponsuksili, S., Zerbe, H., Schuberth, H.-J., Brunner, R.M. and Seyfert, H.-M., 2017. Differentiating Staphylococcus aureus from Escherichia coli mastitis: S. aureus triggers unbalanced immune-dampening and host cell invasion immediately after udder infection. Scientific Reports 7: 4811. https:// doi.org/10.1038/s41598-017-05107-4

Henrotin, Y., Patrier, S., Pralus, A., Roche, M. and Nivoliez, A., 2019. Protective actions of oral administration of Bifidobacterium longum CBi0703 in spontaneous osteoarthritis in Dunkin Hartley guinea pig model. Cartilage 1947603519841674. https://doi. org/10.1177/1947603519841674

Huynh, H.T., Robitaille, G. and Turner, J.D., 1991. Establishment of bovine mammary epithelial cells (MAC-T): an in vitro model for bovine lactation. Experimental Cell Research 197: 191-199. https:// doi.org/10.1016/0014-4827(91)90422-q

Jensen, G.S., Cash, H.A., Farmer, S. and Keller, D., 2017. Inactivated probiotic Bacillus coagulans GBI-30 induces complex immune activating, anti-inflammatory, and regenerative markers in vitro. Journal of Inflammation Research 10: 107-117. https://doi. org/10.2147/JIR.S141660

Klostermann, K., Crispie, F., Flynn, J., Ross, R.P., Hill, C. and Meaney, W., 2008. Intramammary infusion of a live culture of Lactococcus lactis for treatment of bovine mastitis: comparison with antibiotic treatment in field trials. Journal of Dairy Research 75: 365-373. https://doi.org/10.1017/S0022029908003373 
Malvisi, M., Stuknytė, M., Magro, G., Minozzi, G., Giardini, A., De Noni, I. and Piccinini, R., 2016. Antibacterial activity and immunomodulatory effects on a bovine mammary epithelial cell line exerted by nisin A-producing Lactococcus lactis strains. Journal of Dairy Science 99: 2288-2296. https://doi.org/10.3168/jds.2015-10161

Mignacca, S.A., Dore, S., Spuria, L., Zanghì, P., Amato, B., Duprè, I., Armas, F., Biasibetti, E., Camperio, C., Lollai, S.A., Capucchio, M.T., Cannas, E.A., Lo Marco Presti, V. and Marianelli, C., 2017. Intramammary infusion of a live culture of Lactococcus lactis in ewes to treat staphylococcal mastitis. Journal of Medical Microbiology 66: 1798-1810. https://doi.org/10.1099/jmm.0.000641

Nader-Macías, M.E.F., Otero, M.C., Espeche, M.C. and Maldonado, N.C., 2008. Advances in the design of probiotic products for the prevention of major diseases in dairy cattle. Journal of Industrial Microbiology and Biotechnology 35: 1387-1395. https://doi. org/10.1007/s10295-008-0438-2

Pellegrino, M., Berardo, N., Giraudo, J., Nader-Macías, M.E.F. and Bogni, C., 2017. Bovine mastitis prevention: humoral and cellular response of dairy cows inoculated with lactic acid bacteria at the dryoff period. Beneficial Microbes 8: 589-596. https://doi.org/10.3920/ BM2016.0194

Pericolini, E., Gabrielli, E., Ballet, N., Sabbatini, S., Roselletti, E., Cayzeele Decherf, A., Pélerin, F., Luciano, E., Perito, S., Jüsten, P. and Vecchiarelli, A., 2017. Therapeutic activity of a Saccharomyces cerevisiae-based probiotic and inactivated whole yeast on vaginal candidiasis. Virulence 8: 74-90. https://doi.org/10.1080/2150559 4.2016.1213937

Peton, V. and Le Loir, Y., 2014. Staphylococcus aureus in veterinary medicine. Infection, Genetics and Evolution 21: 602-615. https:// doi.org/10.1016/j.meegid.2013.08.011

Piqué, N., Berlanga, M. and Miñana-Galbis, D., 2019. Health benefits of heat-killed (tyndallized) probiotics: an overview. International Journal of Molecular Sciences 20: 2534. https://doi.org/10.3390/ ijms20102534.

Roselletti, E., Sabbatini, S., Ballet, N., Perito, S., Pericolini, E., Blasi, E., Mosci, P., Cayzeele Decherf, A., Monari, C. and Vecchiarelli, A., 2019. Saccharomyces cerevisiae CNCM I-3856 as a new therapeutic agent against oropharyngeal candidiasis. Frontiers in Microbiology 10: 1469. https://doi.org/10.3389/fmicb.2019.01469

Roussel, P., Cunha, P., Porcherie, A., Petzl, W., Gilbert, F.B., Riollet, C., Zerbe, H., Rainard, P. and Germon, P., 2015. Investigating the contribution of IL-17A and IL-17F to the host response during Escherichia coli mastitis. Veterinary Research 46: 56. https://doi. org/10.1186/s13567-015-0201-4

Sanders, M.E., Merenstein, D.J., Ouwehand, A.C., Reid, G., Salminen, S., Cabana, M.D., Paraskevakos, G. and Leyer, G., 2016. Probiotic use in at-risk populations. Journal of the American Pharmacists Association 56: 680-686. https://doi.org/10.1016/j.japh.2016.07.001
Schukken, Y.H., Günther, J., Fitzpatrick, J., Fontaine, M.C., Goetze, L., Holst, O., Leigh, J., Petzl, W., Schuberth, H.-J., Sipka, A., Smith, D.G.E., Quesnell, R., Watts, J., Yancey, R., Zerbe, H., Gurjar, A., Zadoks, R.N. and Seyfert, H.-M., 2011. Host-response patterns of intramammary infections in dairy cows. Veterinary Immunology and Immunopathology 144: 270-289. https://doi.org/10.1016/j. vetimm.2011.08.022

Schwendicke, F., Horb, K., Kneist, S., Dörfer, C. and Paris, S., 2014. Effects of heat-inactivated Bifidobacterium BB12 on cariogenicity of Streptococcus mutans in vitro. Archives of Oral Biology 59: 13841390. https://doi.org/10.1016/j.archoralbio.2014.08.012

Sengupta, R., Altermann, E., Anderson, R.C., McNabb, W.C., Moughan, P.J. and Roy, N.C., 2013. The role of cell surface architecture of lactobacilli in host-microbe interactions in the gastrointestinal tract. Mediators of Inflammation 2013: 237921. https://doi. org/10.1155/2013/237921

Souza, R.F.S., Jardin, J., Cauty, C., Rault, L., Bouchard, D.S., BermúdezHumarán, L.G., Langella, P., Monedero, V., Seyffert, N., Azevedo, V., Le Loir, Y. and Even, S., 2017. Contribution of sortase SrtA2 to Lactobacillus casei BL23 inhibition of Staphylococcus aureus internalization into bovine mammary epithelial cells. PLoS ONE 12: e0174060. https://doi.org/10.1371/journal.pone.0174060

Souza, R.F.S., Rault, L., Seyffert, N., Azevedo, V., Le Loir, Y. and Even, S., 2018. Lactobacillus casei BL23 modulates the innate immune response in Staphylococcus aureus-stimulated bovine mammary epithelial cells. Beneficial Microbes 9: 985-995. https:// doi.org/10.3920/BM2018.0010

Taverniti, V. and Guglielmetti, S., 2011. The immunomodulatory properties of probiotic microorganisms beyond their viability (ghost probiotics: proposal of paraprobiotic concept). Genes and Nutrition 6: 261-274. https://doi.org/10.1007/s12263-011-0218-x

Terpou, A., Papadaki, A., Lappa, I.K., Kachrimanidou, V., Bosnea, L.A. and Kopsahelis, N., 2019. Probiotics in food systems: significance and emerging strategies towards improved viability and delivery of enhanced beneficial value. Nutrients 11. https://doi.org/10.3390/ nu11071591

Védrine, M., Berthault, C., Leroux, C., Répérant-Ferter, M., Gitton, C., Barbey, S., Rainard, P., Gilbert, F.B. and Germon, P., 2018. Sensing of Escherichia coli and LPS by mammary epithelial cells is modulated by O-antigen chain and CD14. PLoS ONE 13: e0202664. https:// doi.org/10.1371/journal.pone.0202664.

Wang, L., Si, W., Xue, H. and Zhao, X., 2017. A fibronectin-binding protein (FbpA) of Weissella cibaria inhibits colonization and infection of Staphylococcus aureus in mammary glands. Cellular Microbiology 19: e12731. https://doi.org/10.1111/cmi.12731

World Health Organization (WHO), 2015. Global action plan on antimicrobial resistance. World Health Organization, Geneva, Switzerland. Available at: https://apps.who.int/iris/handle/ $10665 / 193736$ 
Blanchet, F., Rault, L., Peton, V., Le Loir, Y., Blondeau, C., Lenoir, L., Dubourdeaux, M. and Even, S., 2020. Heat inactivation partially preserved barrier and immunomodulatory effects of Lactobacillus gasseri LA806 in an in vitro model of bovine mastitis. Beneficial Microbes 12: 95-106. doi: https://doi.org/10.3920/BM2020.0146.

In Figure 2 some bars were swapped unfortunately. In Figure 3 some of the labels on the x-axis were incorrect. The correct figures are presented here.
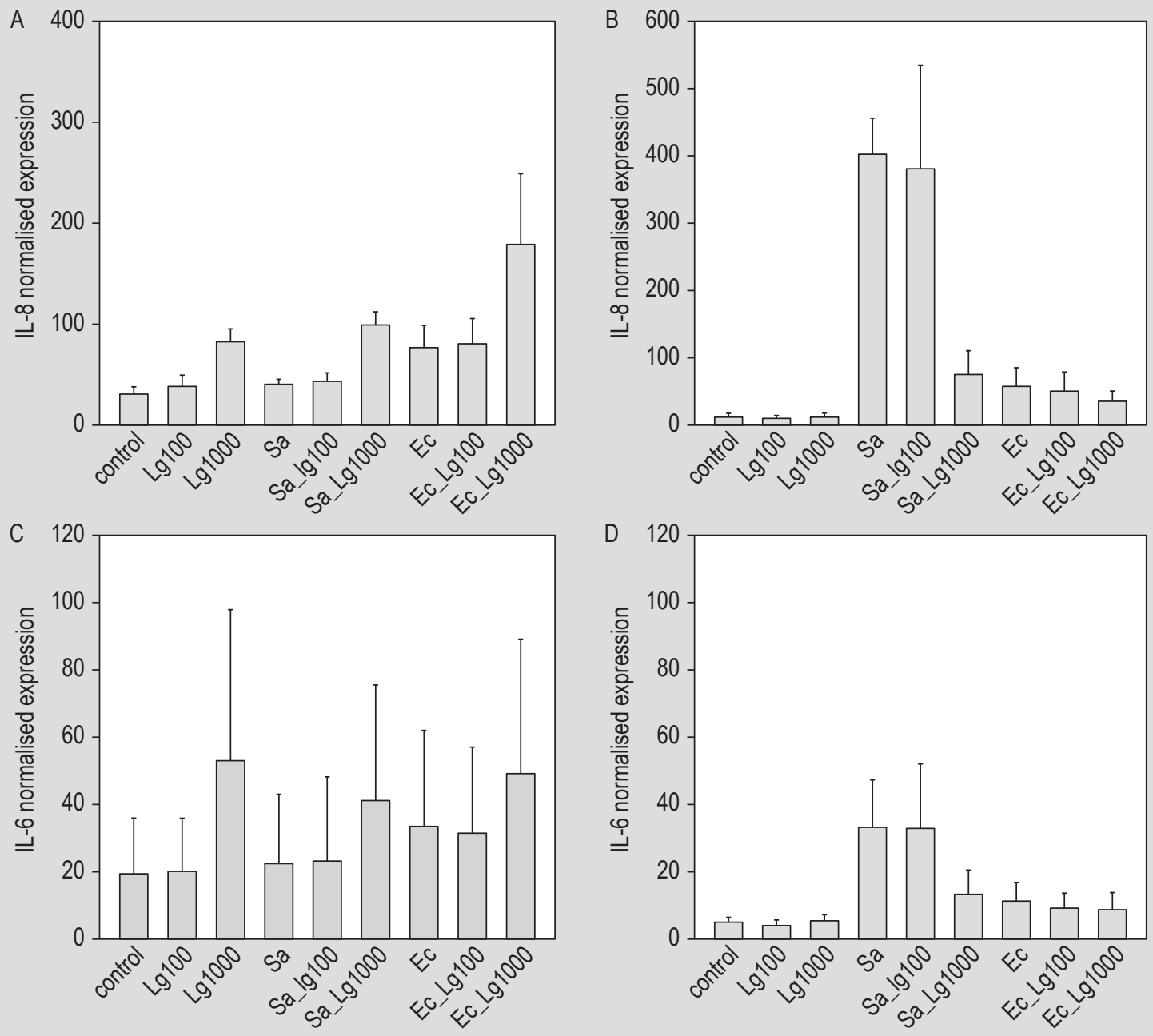

Figure 2. Impact of Lactobacillus gasseri LA806 (Lg) on interleukin (IL)-8 (A, B), IL-6 (C, D), tumour necrosis factor (TNF)- $\alpha$ (E, F) and IL-1a (G, H) expression by bovine mammary epithelial cells (bMECs) during infection by Staphylococcus aureus NB305 (Sa) or Escherichia coli P4 (Ec). bMECs were stimulated with pathogens at a MOI of 30:1 either alone or in the presence of $L$. gasseri LA806 at a MOI of 100:1 and 1.000:1. Expression was measured at $2 \mathrm{~h}(\mathrm{~A}, \mathrm{C}, \mathrm{E}, \mathrm{G})$ and $8 \mathrm{~h}(\mathrm{~B}, \mathrm{D}, \mathrm{F}, \mathrm{H})$ post-infection. Expression was determined as the normalised expression with regard to three control genes. Each experiment was performed in triplicate. The effects of each factor (i.e. the presence of a pathogen or L. gasseri LA806) and interactions between the two factors were assessed using a two-way analysis of variance. MOI = multiplicity of infection. 

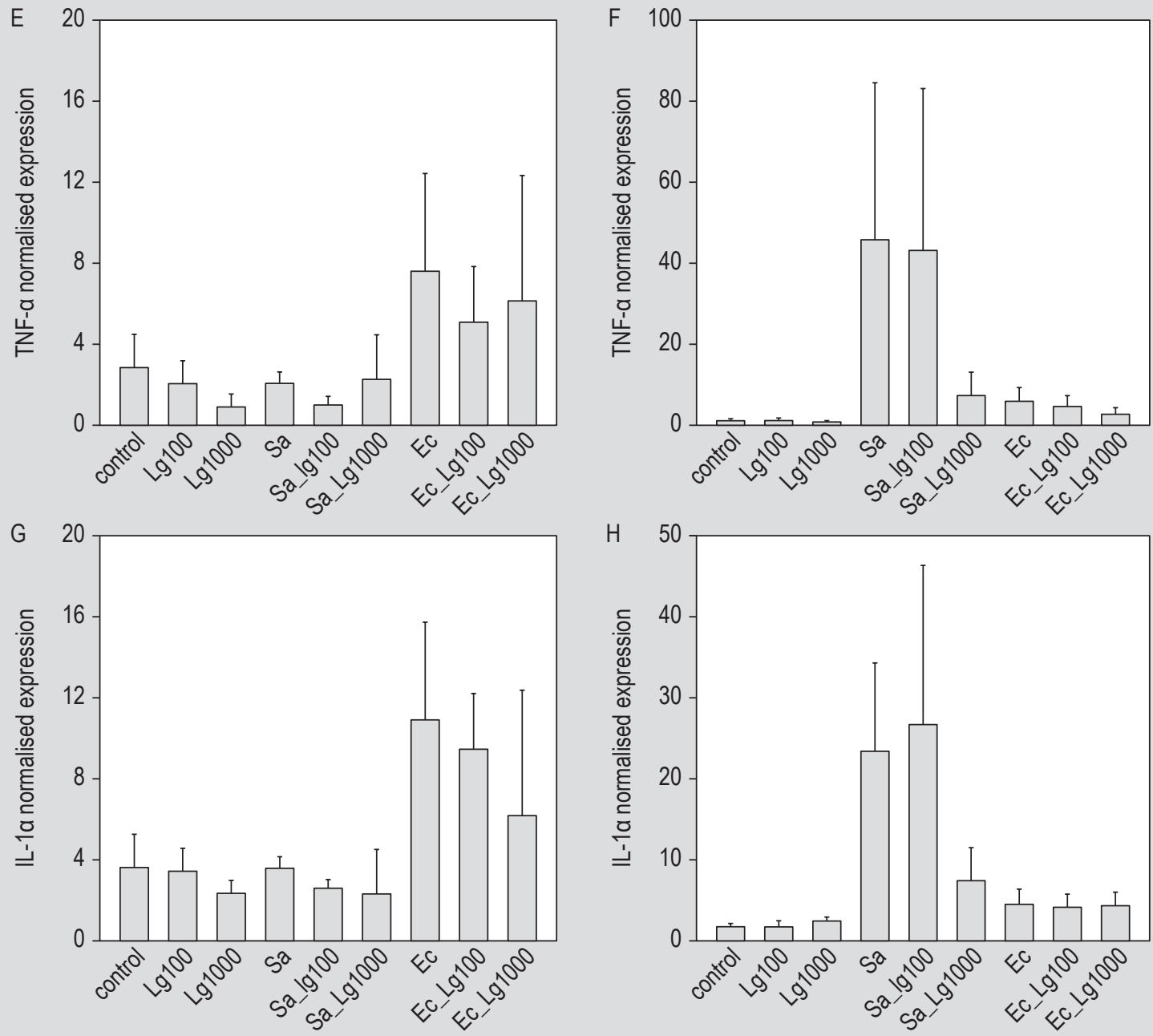

Figure 2. Continued.
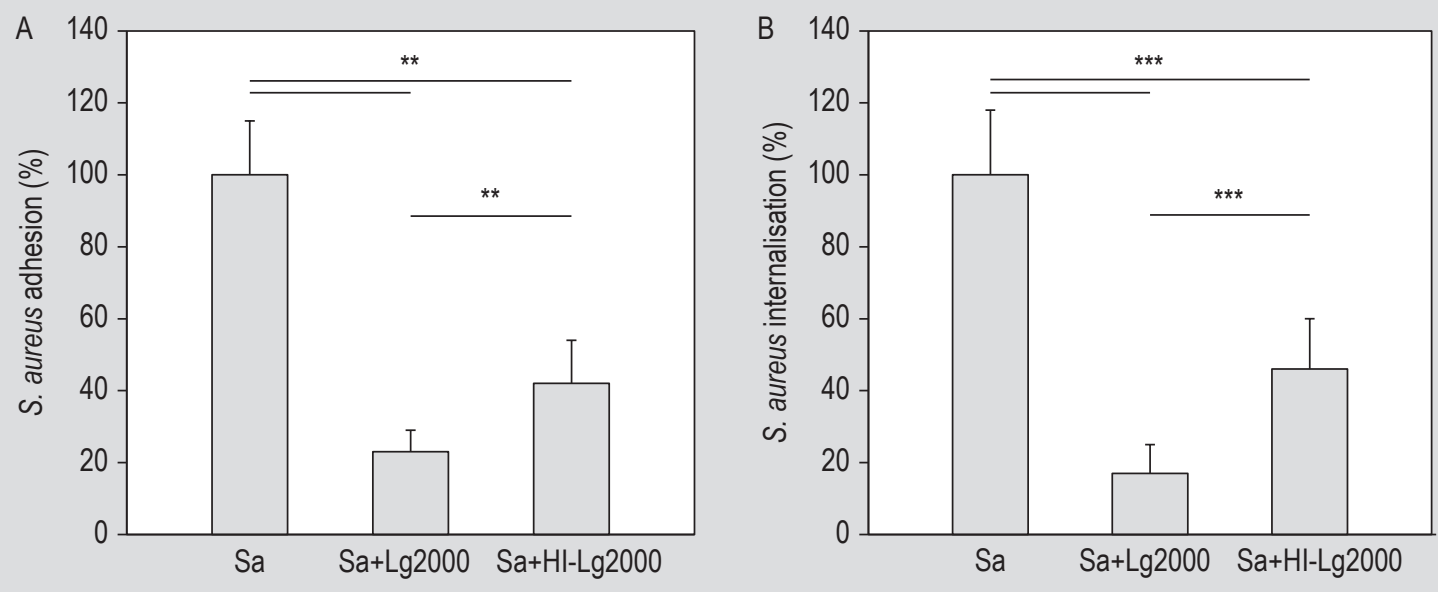

Figure 3. Effect of heat-inactivated (HI) Lactobacillus gasseri LA806 on Staphylococcus aureus N305 adhesion to and internalisation into bovine mammary epithelial cells. S. aureus adhesion $(A)$ and internalisation $(B)$ rates were measured $1 \mathrm{~h}$ and $2 \mathrm{~h}$ post-infection, respectively. S. aureus NB305 (Sa) was used at a MOI of 100:1 and L. gasseri LA806, either heat-inactivated (HI-Lg) or alive (Lg), at a MOI of 2000:1. The results of adhesion and internalisation assays with $S$. aureus alone were used as the reference (control). Rates were then defined as the adhered or internalised S. aureus NB305 population in the presence of $L$. gasseri LA806 either heat-inactivated or live, relative to the adhered or internalised S. aureus NB305 population of the reference experiment. Data are presented as means \pm standard deviations. Each experiment was performed in triplicate and differences between groups were assessed using a one-way analysis of variance followed by Tukey's range test. ${ }^{*} P<0.005,{ }^{* *} P<0.0005$. MOl: multiplicity of infection. 